\title{
Designing Ordering and Inventory Management Methodologies for Purchased Parts
}

AUTHORS

Arnold Looman

is a logistics consultant for Philips Electronics in Winterswijk, the Netherlands.

\section{Frans A.J. Ruffini}

is a logistics manager for Feijen Staalservice BV in Maastricht, the Netherlands.

\section{Luitzen de Boer}

is an assistant professor of purchasing and management science at the University of Twente in Enschede, the Netherlands.

This article presents a method for redesigning the ordering and inventory management methodologies for purchased parts in a manufacturing firm. The method takes the perspective of the purchasing and logistics manager, defines clusters of purchased items, and subsequently assigns each cluster to a suitable way of ordering and inventory management. An application of the method, resulting in an 11 percent overall supply costs reduction proSUMMARY posal, is presented. The application shows that the method is particularly suitable for a first, rough redesign of the existing - usually undifferentiated - way of ordering and managing inventory. In addition, the method may provide a clear format for collaboration among the various disciplines involved in the redesign process.

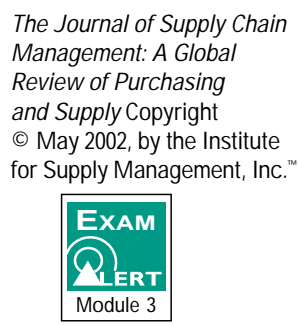

There seems to be widespread agreement on the potential advantages of integrating or at least coordinating intra- and inter-organizational functions under the umbrella of supply chain management (e.g., Ellram and Cooper 1990; Landeros et al. 1995; Ellram and Hendrick 1995; Graham et al. 1994. The actual creation of interfaces between the individual links, however, is problematic (Jahnukainen and Lahti 1999) and the available literature does not seem to offer a great deal of help, especially not for individual managers. While Fawcett and Fawcett (1995) emphasized the importance of an integrated approach involving purchasing, logistics, and operations, the corresponding fields of literature still seem to follow separate ways. For example, Beamon (1998) concluded that operations management literature lacks sufficient design techniques for operational izing its concepts. Maloni and Benton (1997) concluded that the vast majority of contributions in operations research still focus on one-product-one-supplier settings, which is not immediately relevant for a manager facing several thousands of items from more than a hundred suppliers. The purchasing and supply literature (see, for example, van Weele 1994) recognizes the perspective of materials managers, yet is less clear on the operational interface between incoming goods and production.

Therefore, this article takes the viewpoint of a manager who has to deal with many items from multiple suppliers and who has to decide which ways of ordering, managing inventory, and expediting should be used for the various categories of purchased items. A design method for supporting managers in making these decisions is proposed.

The article begins with a discussion of the terminology and starting points underlying the design method, followed by a detailed presentation of the design method itself. The method is subsequently illustrated by examples from a practical application. The article concludes with a discussion of the results and implications for further research. 


\section{DEFINITION OF TERMS AND STARTING POINTS FOR THE DESIGN METHOD}

An ordering and inventory management (OIM) method is defined here as a particular combination of (1) a way of releasing replenishment orders for a purchased item, (2) a way of determining the quantity to be ordered (i.e., lot sizing) for that item, and (3) a way of expediting the timely delivery of the item by the supplier. In theory, many different OIM methods can be conceived of (see Figure 1).

The starting point in this article is the setting of a manufacturing firm which procures materials and items that vary in terms of such factors as demand, demand variability, size, physical appearance, and monetary value. In such a setting, it makes sense to consider different OIM methods for different purchased items. For example, for purchased items of exceptional monetary value and a high but stable demand, it may be beneficial to use an OIM method that seeks relatively low levels of inventory. Similarly, other aspects may be specifically important for other items, for example the cost of releasing and handling orders.

The total set of OIM methods a firm uses for different (categories of) items is called the OIM configuration. The design of the OIM configuration is a complicated task because of (1) the large number of options available in terms of alternative OIM methods; (2) the presence of several criteria that may have to be taken into account when evaluating different OIM methods for a certain purchased part; (3) the often large number of items that must be decided upon; and (4) the restrictions that follow from decisions about the supplier base and the supply strategies to be pursued. Consistent with Simon (1993), the method described in this article is concerned with procedural rationality (i.e, how to decide) rather than substantive rationality (i.e, what to decide).

As becomes clear from Figure 2, instead of analyzing all theoretically possible OIM methods for each individual purchased item, the method simplifies this huge task by decomposing the problem into more manageable subproblems. The next section explains in more detail how each subproblem is tackled. The OIM configuration design method presented is subject to decisions regarding the specifications of the purchased items, the suppliers that have been selected, as well as the contracts that have been negotiated. In addition, it is assumed that design of the OIM configuration has to comply with the firm's sourcing and supplier management strategies.

\section{A STEPWISE APPROACH TO DESIGNING AN OIM CONFIGURATION}

In this section, the stepwise approach leading to the ultimate design of an OIM configuration is described (see Figure 3 ).

The six steps are explained in more detail in the following section.

\section{Figure 1}

\section{THEORETICAL COMBINATIONS OF METHODS FOR ORDER RELEASING, LOT SIZING, AND EXPEDITING ${ }^{1}$}

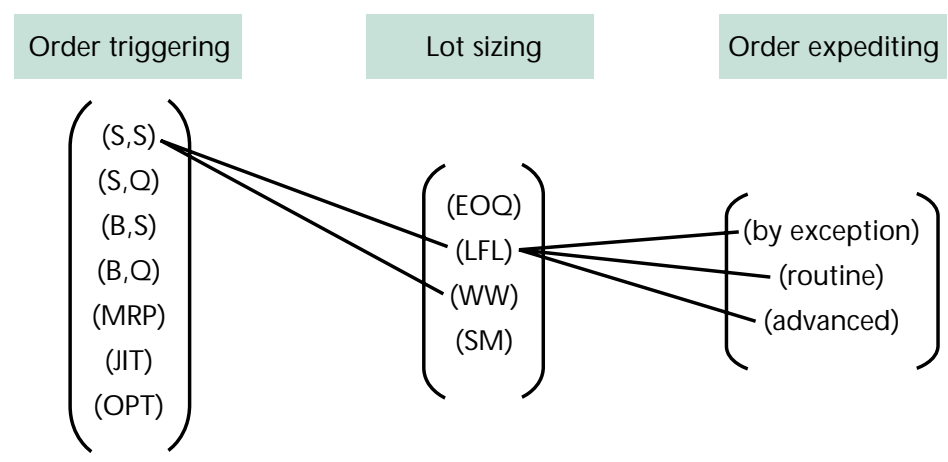

Figure 2

APPROACH FOR DECOMPOSING THE PROBLEM OF DESIGNING AN OIM CONFIGURATION

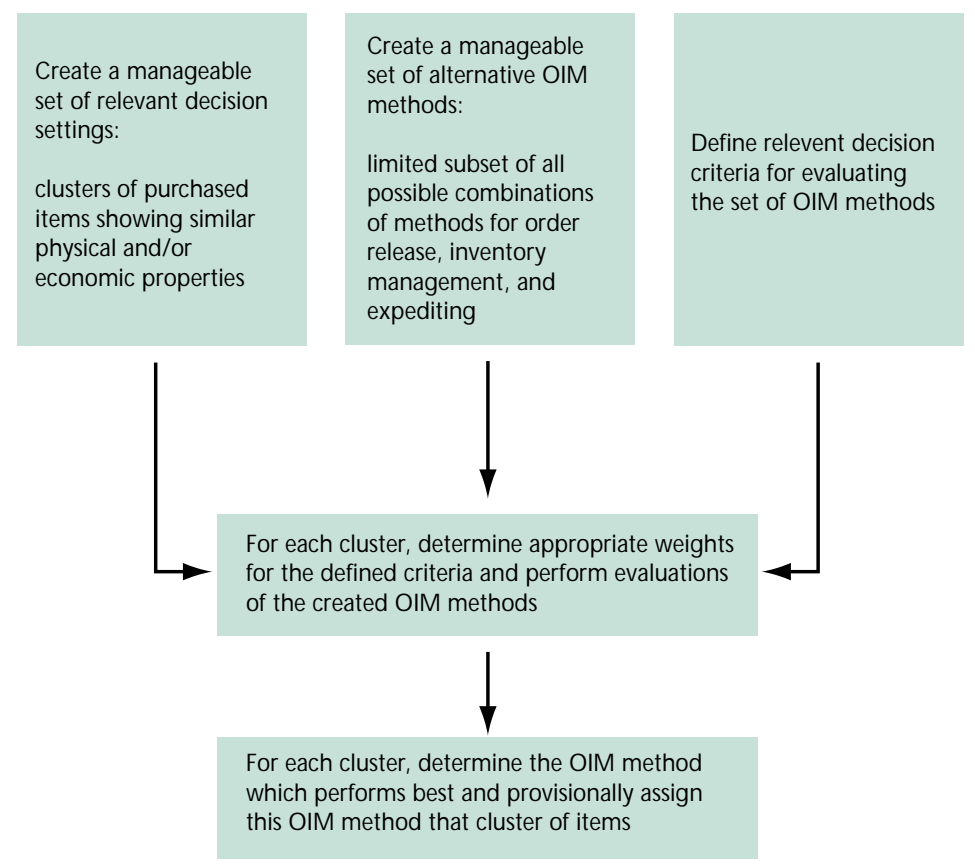

\footnotetext{
${ }^{1}(\mathrm{~s}, \mathrm{~S})=$ (reorder interval, order up to level)

$(\mathrm{s}, \mathrm{Q})=$ (reorder interval, order quantity)

$(B, S)=($ reorder level, order up to level $)$

$(B, Q)=($ reorder level, order quantity)

$M R P=$ Material Requirements Planning, JIT = Just In Time,

OPT =Optimized Production Technology, EOQ =Economic Order

Quantity, LFL = Lot For Lot, WW =Wagner Whitin algorithm,

SM = Silver Meal al gorithm

Expediting by exception $=$ no order expediting unless problems are reported

Routine expediting =standard, simple check with supplier a few days before delivery due date

Advanced expediting = extensive and dedicated monitoring using predefined milestones
} 
Figure 3

\section{A STEPWISE APPROACH TO DESIGNING AN OIM CONFIGURATION}

1: Constructing a manageable set of alternative OIM methods
2: Creating a manageable set of decision settings
Step $2 a \quad$ Dividing the purchased parts assortment into clusters of similar parts
Step $2 \mathrm{~b} \quad$ Mapping the current OIM configuration
3: Possibly excluding clusters from further consideration
4: Defining relevant evaluation criteria
5: Evaluating and provisionally assigning OIM methods to clusters
Step $5 a \quad$ Determining the criteria weights for each cluster
Step $5 b \quad$ Evaluation of the OIM methods on the weighted criteria per cluster
Step 5c Performing sensitivity analysis on the evaluation
Step $5 d \quad$ Provisional assignment of the highest-scoring OIM method per cluster
6: Final OIM configuration design based on operational cost/benefit analysis

Figure 4

PROCEDURES FOR CREATING OIM METHODS

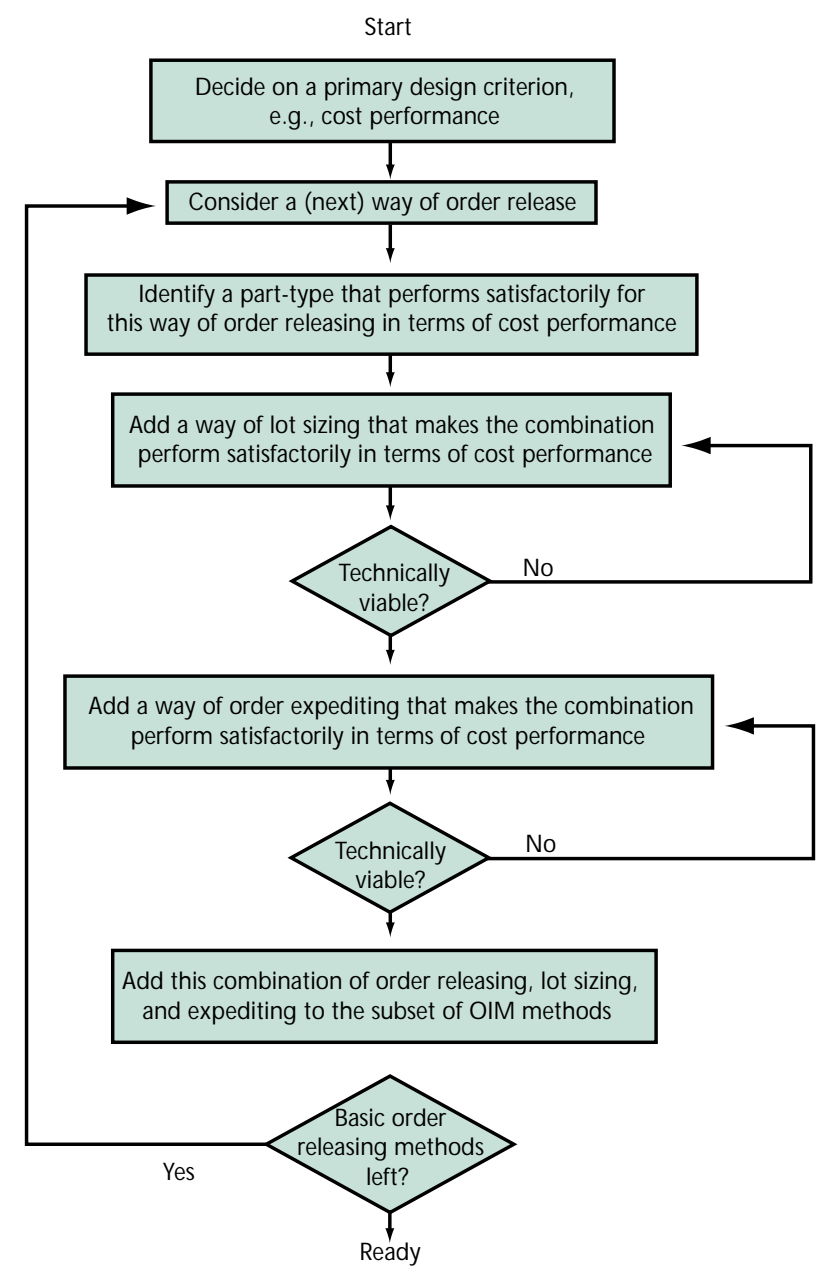

\section{Step 1: Constructing a manageable set of} alternative OIM methods

The procedure for selecting a useful subset from all possible OIM methods is shown in Figure 4.

The procedure shown in Figure 4 is heuristic and may produce different basic OIM methods depending on which element of such a method is considered first, i.e., the way of order releasing, the way of lot sizing, or the way of expediting. The purpose of the procedure is to produce a limited number of OIM methods for different typically purchased parts that are expected to yield acceptable results with respect to at least one important criterion, in this case operational cost performance. It is stressed that the procedure as such, rather than the specific outcome described here, is part of the OIM configuration design method.

\section{Step 2: Creating a manageable set of decision settings}

A huge number of purchased parts does not allow for a part-specific evaluation process with regard to the most suitable OIM method for that part. Therefore, the design method involves a clustering of the purchased parts. Subsequently, evaluation of the different OIM methods will take place for each cluster of items. The question arises, which criteria should be used for this clustering? In this article, this is regarded as an empirical matter. In general, properties like physical size and shape, weight, monetary value, degree to which the part is hazardous or fragile, annual demand, and fluctuations in demand are likely to be relevant for any set of criteria a firm may want to use to evaluate its operations in terms of overall logistic effectiveness and efficiency (Coyle et al. 1996). Statistical techniques like cluster analysis may be used to create a natural clustering of components based on the characteristics specified.

\section{Step 3: Possibly excluding cluster from further consideration}

There may be several pragmatic reasons for not taking a cluster of components into further consideration, for example:

- Demand for the items within a cluster has declined strongly in the past and/or future demand is unlikely.

- A switch to another OIM method clearly requires excessive efforts and investments.

- The current OIM method must be maintained, for example due to limited storage life, explosiveness, or government restrictions with respect to storage.

- Another OIM method is not possible because of quality system considerations.

\section{Step 4: Defining relevant evaluation criteria}

The OIM configuration design aims to take into account multiple criteria when evaluating the OIM methods for 
each cluster. Given the context of day-to-day supply of goods, the criteria are likely to fall into such categories as ordering costs, handling costs, inventory costs, throughput time, service level, and so on. A useful tool for systematically arriving at a comprehensive yet manageable set of criteria may be the Value Focused Thinking (VFT) approach (Keeney 1994). By involving representatives from purchasing, operations, and marketing in the VFT process, additional mutual understanding and commitment may be gained as well.

\section{Step 5: Initial allocation of an OIM method to each cluster}

For each cluster, the basic OIM methods defined in Step 1 are now evaluated with regard to the criteria specified in the previous step. In this way, a tentative assignment of an OIM method type to each cluster is achieved (see Figure 5).

Weighing of the criteria is done for each cluster separately as the differences betwen the clusters are likely to correspond to different sets of relative weights of the criteria. For example, a criterion like "inventory costs" may be especially relevant for purchased items of considerable value and may therefore be assigned a relatively high weight for clusters containing expensive items. This step can be handled very efficiently by using established MultiCriteria Decision Making (MCDM) tools like Analytic Hierarchy Process (AHP) (see Saaty 1980). For each cluster, using AHP, both the weighing of the criteria and the rating of the OIM methods on these criteria can be performed requiring only verbal, qualitative pair-wise comparisons. Obviously, quantitative data (insofar as readily available) may support these comparisons. The AHP method ensures a consistent set of judgments and easily allows extensive and graphical sensitivity analysis. Other MCDM tools may be used as well, e.g., MAUT (Keeney, Raiffa, and Meyer 1976) or SMART (Von Winterfeldt and Edwards 1986). For each cluster, it is determined which of the OIM methods performs best in terms of the scores resulting from applying an MCDM technique.

After assigning the highest-scoring OIM method to each cluster, a possible modification of one or more basic OIM methods into a more specific variant may be necessary. For example, when constructing the set of OIM methods in Step 1, several ways of releasing orders may have seemed equally compatible in an OIM method for the particular purchased part under consideration. At this stage, a choice should made as to which method for order releasing is going to be used. This choice may again require the specification of one or more appropriate criteria.

\section{Step 6: Final OIM configuration design based on a cost/ benefit analysis and conformance with purchasing and supplier management strategies}

So far, the necessary investments, the economies of scale related to limiting the number of different OIM methods,
Figure 5

\section{ASSIGNING THE CLUSTERS TO AN OIM METHOD TYPE}

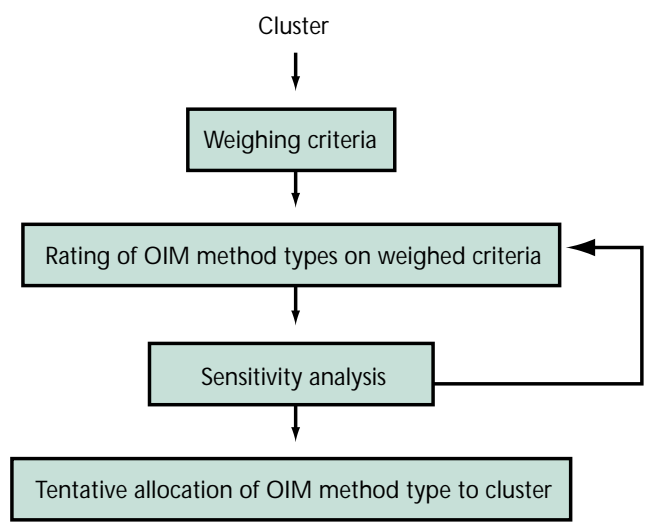

as well as the degree of compatibility with the firm's supplier strategies have not been addressed.

Investment analysis involves evaluating the costs required for switching to the newly proposed OIM method for a certain cluster. Only if the savings - as appropriately defined for the firm under consideration - and the increased revenues in terms of improved customer service outweigh the required investments, should the newly assigned OIM method be implemented. Otherwise, the design process is directed back to Step 5 again. Using this loop, the expected savings of the runner-up OIM method will then be assessed in terms of savings, benefits, and required investments.

In addition, the proposed changes have to be analyzed in light of the current supply base structure and the supplier strategies applied by the company. This may reveal opportunities for economies of scale requiring a modification of the original design. Consider, for example, the case where according to the initial design, 90 percent of the components procured from Supplier $X$ are assigned to OIM method $A$, and the other 10 percent are assigned to OIM Method B. It may then be favorable to procure all of the components by using OIM Method A in order to achieve economies of scale in transport and in managing the supplier. A useful tool for this analysis is the purchasing portfolio approach developed by Kraljic (1983) (see Figure 6).

\section{APPLICATION OF THE DESIGN METHOD IN PRACTICE}

In this section, excerpts of an application of the design method in a Dutch manufacturer of kitchen equipment are presented. The company uses a make-to-order concept for its production operations and carries very few finished goods on stock. The supply of components plays a critical role in keeping the total cost of the order-fulfilling process at a minimum. The (only) OIM method currently in use is based on an MRP system and is used for all components. 
Figure 6 TOOL FOR ANALYSIS OF INITIAL
DESIG N OF OIM CONFIGURATION

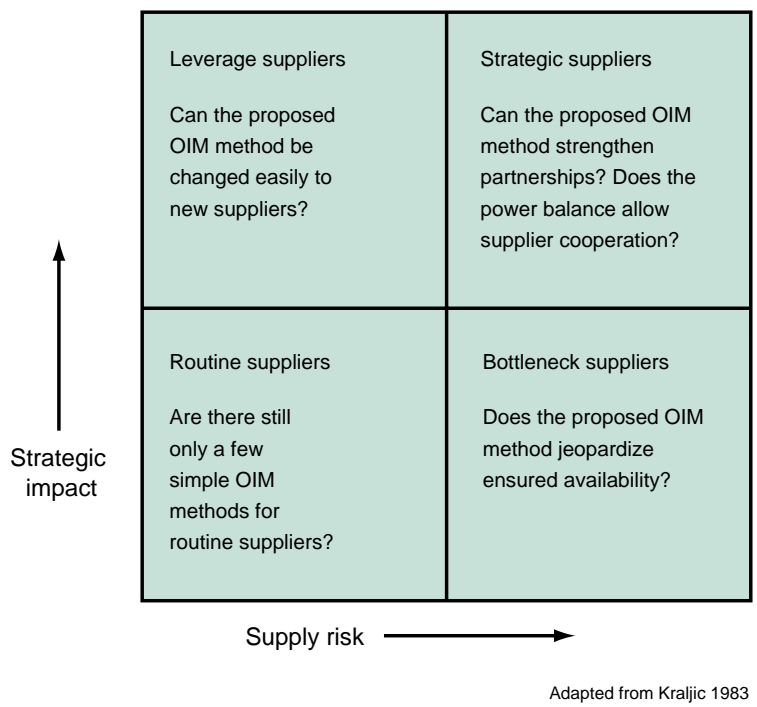

Table I

\section{CHARACTERISTICS OF THE PURCHASED PARTS OF THE CASE FIRM}

\begin{tabular}{lll} 
Characteristic & Diversity & \\
\hline Purchasing price & $<\$ 0.01$ per piece & $>\$ 400$ per piece \\
Geometry & Screws & Glass wool sheets \\
Specificity & Standard components & Order specific \\
Annual demand & $<10$ pieces & $>1$ million pieces \\
Purchased volume & $<\$ 50$ per component & $>\$ 3$ million per \\
& per year & component per year
\end{tabular}

Table II

MAIN OIM METHODS CONSTRUCTED IN STEP 1

\begin{tabular}{|c|c|c|c|}
\hline OIM methods & $\begin{array}{l}\text { Method(s) for } \\
\text { order release }\end{array}$ & $\begin{array}{l}\text { Method(s) } \\
\text { for lot sizing }\end{array}$ & $\begin{array}{l}\text { Method(s) for } \\
\text { order expediting }\end{array}$ \\
\hline $\begin{array}{l}\text { SIC type } \\
\text { (Model for static and } \\
\text { stochastic demand for } \\
\text { one location) }\end{array}$ & SS, sQ & $\begin{array}{l}\text { EOQ-based } \\
\text { methods }\end{array}$ & $\begin{array}{l}\text { Exception } \\
\text { expediting }\end{array}$ \\
\hline $\begin{array}{l}\text { MRP/ERP type } \\
\text { (Model for dynamic } \\
\text { and deterministic } \\
\text { demand for one } \\
\text { location) }\end{array}$ & MRP I & $\begin{array}{l}\text { LFL, WW, SM, } \\
\text { and EOQ based } \\
\text { methods }\end{array}$ & $\begin{array}{l}\text { Routine status } \\
\text { check and } \\
\text { advanced status } \\
\text { check }\end{array}$ \\
\hline
\end{tabular}

JIT type

(Model for static and deterministic demand for one location)

$\begin{array}{lll}\text { JIT } & \text { Continuously } & \text { Exception } \\ \text { lower lot sizes } & \text { expediting }\end{array}$

The company's annual purchase volume is close to $\$ 24$ million, consisting of electronic assemblies, induction generators, ceran glass, and steel, see Table I.

The redesign of the OIM configuration for this company is now described.

\section{Step 1: Constructing a manageable set of OIM methods}

Application of the procedure shown in Figure 4 resulted in four basic types of OIM methods (see Table II).

For notational convenience, these OIM methods are referred to as $\mathrm{SIC}^{2}, \mathrm{MRP}$, ERP, and JIT OIM method types, following the respective concepts they are based on. This means that in this design method, MRP and ERP are considered to be similar. It is assumed that each of these OIM methods is technically viable and consists of a combination of ways for order releasing, lot sizing, and order expediting that shows sufficiently low overall operational costs.

\section{Step 2: Creating a manageable set of decision settings}

In this case, purchasing price, physical product volume per dollar value, and annual demand were considered relevant cluster criteria. The clusters were created by arbitrarily setting interval values for the criteria "price" and "annual demand" and assigning each item accordingly (see Table III). The clustering shown here was made for low-volume as well as high-volume components separately, thus resulting in a total of 32 clusters, i.e., 16 "low-volume" clusters and 16 "high-volume" clusters.

Obviously, the 32 clusters strongly differed with respect to performance on the cluster criteria. However, the company used highly similar OIM methods for all clusters. For example, extremely valuable and voluminous items were treated in the same way as cheap and small items. This finding clearly justified a search for a more balanced, differentiated approach.

\section{Step 3: Possibly excluding clusters from further consideration}

The clusters showing a weekly demand of 0 to 1 were excluded from further consideration, because these components would no longer be procured in the future.

\section{Step 4: Defining relevant decision criteria}

In this case, only cost-related criteria were defined. The underlying assumption was that possible customer service related criteria would indirectly be covered by cost criteria. For example, an OIM method that performs poorly on a criterion like "supply flexibility" due to using high and fixed order quantities is assumed to perform poorly on a criterion like "inventory costs" or "stock-out costs." The set of criteria used in the case was: (1) purchasing

\footnotetext{
${ }^{2}$ SIC = Statistical Inventory Control, $\mathrm{ERP}=$ Enterprise Resource Planning
} 
costs, i.e., cost of placing orders; (2) costs of handling (including receiving and storing the items); (3) costs of holding inventory; and (4) costs of stock-out (shortage costs).

\section{Step 5: Provisional assignment of an OIM method to each cluster}

For each of the remaining clusters, an appropriate set of weights of the evaluation criteria was determined using the AHP-based software package ExpertChoice. For example, for the high-price/high-volume clusters, the cost of holding turned out to be the most important criterion. On the other hand, the costs of handling and operational purchasing activities were considered more important for low-price/low-volume clusters. Hence, the AHP method was used to pair-wise evaluate the criteria in terms of their relative importance and generate appropriate weights.

Subsequently, for each cluster, AHP was used to rate the performance of the three basic OIM methods on the criteria using the weights for that cluster (see also Figure 7).

The final outcome was as follows: the SIC method types showed the highest ratings for low-price clusters, primarily because these methods perform especially well on handling cost, which is the most important criterion for these types of clusters. For example, for cluster Al, the AHP rating for the $\mathrm{SIC}$ method type was 0.6 , while the other OIM methods received 0.27 and 0.13 , respectively.

The MRP/ERP method type received the highest ratings for the high-price and/or high-volume clusters. This primarily follows from this method's strong performance in terms of holding cost as well as on handling and purchasing costs. In addition, this method offers good opportunities for order control by the central management system.

The JIT method type was assigned to the clusters containing very expensive parts as well as very high demand. For these clusters, possible savings on holding costs are huge.

Subsequently, for clusters assigned to the SIC and the MRP/ERP method type, a further, more detailed assignment was performed. After all, the basic SIC method included several possible ways of releasing orders, while the MRP method included a number of methods for lot sizing (see also Table II). At this point, each cluster should be assigned one way of order releasing and one way of lot sizing. For example, the s 5 method was assigned to "highvolume variety" SIC clusters. The remaining "Iow-volume variety" clusters were coupled with SQ methods. More specifically, the so-called "two-bin" variant of the sQ method was assigned to high-demand clusters, whereas the "standard" sQ method was assigned to low-demand clusters. ${ }^{3}$

\footnotetext{
${ }^{3}$ In the standard SQ method, the fixed order quantity Q is calculated on an Economic Order Quantity (EOQ) basis, while the two-bin variant uses a convenient standard quantity close to the EOQ, for example full bin loads.
}

Table III

\section{CLUSTERING OF THE PURCHASED COMPONENTS}

\begin{tabular}{|c|c|c|c|c|}
\hline & $<2.50$ & $\begin{array}{l}\geq f 2.50 \\
<f 15.00\end{array}$ & 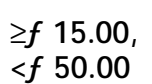 & $\geq 50.0$ \\
\hline \multicolumn{5}{|l|}{ Usage per week } \\
\hline 0 to 1 & Al & $\mathrm{Bl}$ & $\mathrm{Cl}$ & $\mathrm{DI}$ \\
\hline 1 to 40 & All & Bll & Cll & DII \\
\hline 40 to 200 & All & BIII & CIII & DIII \\
\hline More than 200 & AlllI & BIIII & CIIIII & DIIII \\
\hline
\end{tabular}

\section{Figure 7}

\section{USING AHP IN EVALUATING OIM METHODS}

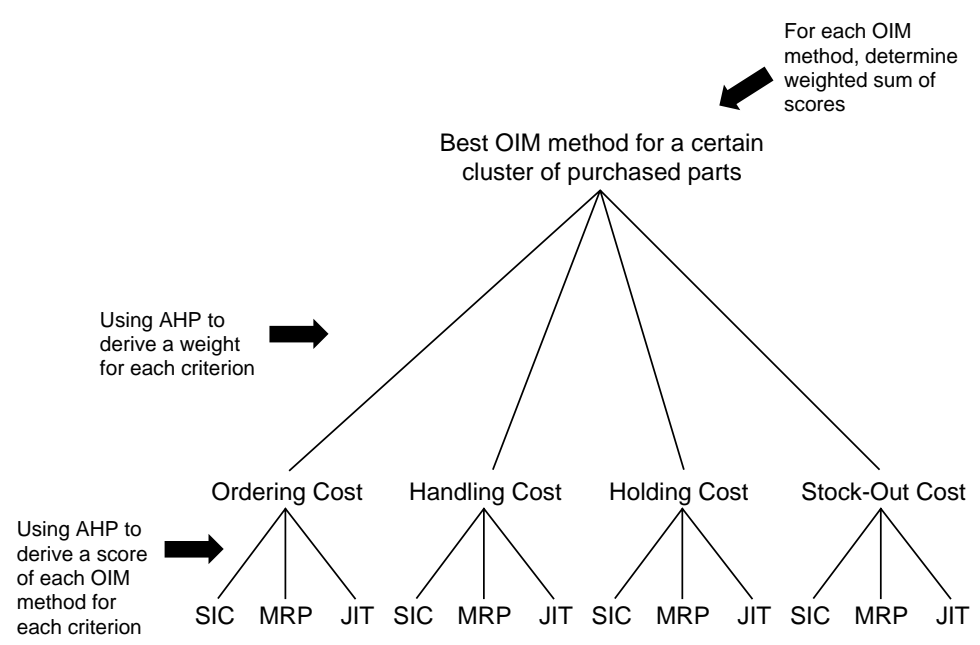

Similarly, the MRP/ERP clusters containing the highest purchasing prices, demand, and/or volume were coupled with the Lot-For-Lot ordering method as this method allows a high supply frequency, which results in low holding cost. The other clusters were coupled with the Silver Meal (SM) ordering method because this method makes it possible to maintain the sum of holding, purchasing, and handling costs on a low level.

\section{Step 6: Final OIM configuration design based on operational cost/benefit analysis}

The cost/benefit analysis reveal ed that regarding the JIT method, reductions in terms of holding costs were likely to be outweighed by the required investments. Furthermore, using the loop back to Step 5, analysis showed that holding costs could also be cut by application of the second-best option, i.e, the MRP/ERP method with the LFL ordering. Therefore, the initial JIT clusters were assigned to the ERP/MRP method instead.

In addition, the cost/benefit analysis suggested that the MRP/ERP-SM method would not result in significant 
benefits. As the loop back to Step 5 did not suggest net improvements either, the current OIM method for these clusters remained unchanged.

Finally, the compatibility check with existing supplier management strategies did not lead to any modifications. The final OIM configuration design is shown in Tables IV and $\mathrm{V}$. Through application of the OIM configuration design method, the kitchen appliances manufacturer switched from one class of highly similar OIM methods for all components, to a differentiated OIM configuration more specifically tailored to the variety in supply cost drivers in the purchased parts.

Table IV

FINAL ASSIGNMENT OF OIM METHODS

TO THE HIGH-VOLUME CLUSTERS

\begin{tabular}{|c|c|c|c|c|}
\hline $\begin{array}{r}\text { Price } \\
\text { Usage per week }\end{array}$ & $<2.50$ & $\begin{array}{l}2.50 \\
<15.00\end{array}$ & $\geq f_{\mathcal{f}} \frac{15.00}{50.00}$ & $\geq 50.00$ \\
\hline$<40$ per week & \multicolumn{4}{|c|}{ MRP/ERP method with current lot sizing method } \\
\hline 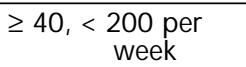 & \multirow{2}{*}{\multicolumn{4}{|c|}{ MRP/ERP method with LFL lot sizing method }} \\
\hline$\geq 200$ per week & & & & \\
\hline
\end{tabular}

Table V

FINAL ASSIGNMENT OF OIM METHODS

TO THE LOW-VOLUME CLUSTERS

\begin{tabular}{|c|c|c|c|c|}
\hline $\begin{array}{r}\text { Price } \\
\text { Usage per week }\end{array}$ & $<2.50$ & $\begin{array}{l}\geq f .50 \\
15.00\end{array}$ & $\geq f^{\geq} \mathbf{f} 15.00$ & $\geq 50.00$ \\
\hline$<40$ per week & $\begin{array}{l}\text { SIC (standard } \\
\text { sQ and SS) } \\
\text { method }\end{array}$ & \multicolumn{2}{|c|}{$\begin{array}{l}\text { MRP/ERP method with current } \\
\text { lot sizing method }\end{array}$} & \\
\hline 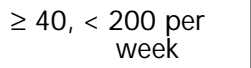 & \multirow{2}{*}{$\begin{array}{l}\text { SIC (“2-bin”- } \\
\text { sQ and SS) } \\
\text { method }\end{array}$} & & \multirow{2}{*}{\multicolumn{2}{|c|}{$\begin{array}{l}\text { MRP/ERP method with } \\
\text { LFL lot sizing method }\end{array}$}} \\
\hline$\geq 200$ per week & & & & \\
\hline
\end{tabular}

Table VI

RESULTS OF THE STEPWISE APPROACH

(IN PERCENTAGE OF TOTAL COSTS)

\begin{tabular}{l|ccccc} 
OIM method & $\begin{array}{l}\text { Impact on } \\
\text { holding } \\
\text { costs }\end{array}$ & $\begin{array}{l}\text { Impact on } \\
\text { handling } \\
\text { costs }\end{array}$ & $\begin{array}{l}\text { Impact on } \\
\text { purchasing } \\
\text { costs }\end{array}$ & $\begin{array}{l}\text { Impact on } \\
\text { shortage } \\
\text { costs }\end{array}$ & $\begin{array}{l}\text { Impact on } \\
\text { total costs }\end{array}$ \\
$\begin{array}{l}\text { "SQ" variant of } \\
\text { SIC method }\end{array}$ & $0 \%$ & $-5 \%$ & $-20 \%$ & $-84 \%$ & $-11 \%$ \\
$\begin{array}{l}\text { "Two-bin" } \\
\text { variant of SIC } \\
\text { method }\end{array}$ & $+18 \%$ & $-16 \%$ & $-32 \%$ & $0 \%$ & $-11 \%$ \\
$\begin{array}{l}\text { Current MRP/ } \\
\text { ERP method }\end{array}$ & $0 \%$ & $0 \%$ & $0 \%$ & $0 \%$ & $0 \%$ \\
$\begin{array}{l}\text { “LFL" variant } \\
\text { of MRP/ERP } \\
\text { method }\end{array}$ & $-33 \%$ & $+31 \%$ & $-29 \%$ & $0 \%$ & $-20 \%$ \\
$\begin{array}{l}\text { Total result of } \\
\text { new OIM } \\
\text { configuration }\end{array}$ & $-16 \%$ & & & & \\
\end{tabular}

The newly designed OIM configuration showed estimated savings as shown in Table VI. The savings were estimated by performing a number of detailed cost analyses for a sample of representative parts from the various clusters and subsequently extrapolating the estimated savings for the entire clusters. Each cost analysis involved a comparison of the old OIM method with the proposed OIM method regarding holding costs, handling costs, ordering costs, and shortage costs.

Note that compared to the current situation, the basic OIM method remains of an MRP/ERP type but the specific way of lot sizing changes to a Lot-For-Lot method while the firm previously categorically relied on an intuitive rule-of-thumb approach. In this way, the frequency of deliveries of these clusters can be increased, resulting in an expected 33 percent drop in holding costs. At first glance, it may be expected that an increase in number of deliveries will raise ordering costs. However, the LFL lot sizing method allows bundling of purchase orders for the same supplier, resulting in a lower ordering cost despite an increase in delivery frequency. Shortage costs are not expected to change, due to reliable forecasts.

Switching to an SIC method for "Iow-value and lowvolume" clusters, and more specifically, the SQ variant (see Table V), is expected to result in lower shortage and purchasing costs. Using the current system, shortage costs were mainly caused by differences between the actual (physical) stock levels and the levels indicated by the firm's information system. By using the sQ variant of the SIC method, the orders will be released by changes in the actual, physical stock level rather than mutations in information systems, and therefore shortages are less likely to occur. After all, information system driven order release is more prone to suffer from entry errors and discrepancies between actual levels and reported stock levels. In addition, as the number of shortages will decrease, fewer short-term (emergency) purchase orders will be necessary, resulting in a 20 percent decrease of ordering costs.

Finally, switching to the "two-bin" variant of the SIC method for clusters of items that are relatively cheap but show moderate to high demand (see Table V) is expected to result in an increase in holding cost because all uncertainty will be covered by building up extra stock. However, ordering costs will decrease because less expediting is required. Furthermore, due to a lower inventory turnover, fewer purchase orders are placed. Also, handling costs will decrease because less handling is needed, due to using the standard bins for reordering. Overall, the two-bin variant is expected to result in lower total costs, as the decrease in handling and ordering costs will outweigh the increase in holding cost, primarily due to the low (financial) value of the purchased parts.

\section{DISCUSSION AND CONCLUSIONS}

The practical application of the OIM configuration design method has shown that considering a few clearly 
different OIM methods al ready offers significant savings potential. It is argued that there are three characteristics of the method proposed in this articlethat contribute to this.

First, the method provides a comprehensive structure for guiding the decisionmaking and design processes surrounding the redesign of an OIM configuration. Any manager facing thousands of different purchased items will need such a structure for managing the complexity of the redesign problem.

Second, the approach enables a manager to identify specific and relevant properties of categories of purchased items and match these with appropriate OIM methods. It enables a manager to find a realistic compromise between designing a part-specific OIM method - which will usually be impossible given the huge number of individual items - and treating all purchased items as if they were completely identical in terms of physical and economic properties. In that respect, the method described here is particularly suitable for a first and rough redesign effort, lifting the usually undifferentiated existing OIM configuration up to a first level of differentiation given the varied nature of the set of purchased parts. Next, more focused and specific continuous improvement projects may be initiated to finetune and optimize the design, for example by considering more detailed subvariants of the few basic OIM methods constructed in the first step of the method.

Third, the OIM configuration design method may provide a clear format for collaboration among the various disciplines involved in the redesign process such as purchasing, materials management, and production/operations. Especially when defining and weighing relevant criteria for evaluating basic OIM methods, group discussion and decisionmaking is facilitated. In addition, a next step may beto extend the method to incorporate involve ment from suppliers and customers in seizing opportunities for further improvement that hinge on cooperation from these parties.

In addition, some issues are identified which may require further attention in other applications and further research in this area. First, the method easily allows for more sophisticated heuristic approaches to be used in each step. For example, instead of the qual itative evaluation of the different OIM methods using AHP, more quantitative optimization techniques could be considered for allocating OIM methods to different clusters of parts, given that the required (detailed) information would be available. This will not change the fundamentals of the method, but it may be a sensible consideration when the existing OIM configuration al ready exhibits considerable differentiation and the problem is one of deciding on specific variants of OIM methods within each cluster rather than assigning basic OIM methods to clusters in the first place.

Also, the method has not been studied over a longer period of time. Doing so may offer valuable insights into the method's ability to cope with the dynamics of new items being introduced, other items becoming obsolete, changes in the supplier base, and so on. Clearly, the method - or at least some steps in it - must be repeated from time to time to accommodate these events.

\section{REFERENCES}

Baily, P. and D. Farmer. Purchasing: Principles and Management, Pitman Publishing, London, 1990.

Beamon, B.M. "Supply Chain Design and Analysis: Models and Methods," International Journal of Production Economics, (55), 1998, pp. 281-294.

Coyle, J.J., E.J. Bardi, and C.J. Langley. The Management of Business Logistics, West Publishing Company, Minneapolis, MN, 1996.

Ellram, L.M. and M.C. Cooper. "Supply Chain Management, Partnerships, and the Shipper-Third Party Relationship," The International Journal of Logistics Management, (1:2), 1990, pp. 1-10.

Ellram, L.M. and T.E. Hendrick. "Partnering Characteristics: A Dyadic Perspective," Journal of Business Logistics, (16:1), 1995, pp. 41-64.

Fawcett, S.E. and S.A. Fawcett. "The Firm as a Value-Added System: Integrating Logistics, Operations and Purchasing," International Journal of Physical Distribution and Logistics Management, (25:5), 1995, pp. 24-42.

Graham, T.S., P.J. Daugherty, and W.N. Dudley. “The Long-Term Strategic Impact of Purchasing Partnerships," International Journal of Purchasing and Materials Management, (30:4), Fall 1994 pp. 13-18.

Jahnukainen, J. and M. Lahti. "Efficient Purchasing in Make-toOrder Supply Chains," International Journal of Production Economics, (59), 1999, pp. 103-111.

Keeney, R.L. "Creativity in Decision Making with Value-Focused Thinking," Sloan Management Review, (35:4), 1994, pp. 33-41.

Keeney, R.L., H. Raiffa, and R.F. Meyer. Decisions with Multiple Objectives: Preferences and Value Trade-Offs, Wiley, New York, NY, 1976.

Kraljic, P. "Purchasing Must Become Supply Management," Harvard Business Review, September-October 1983, pp. 109-117.

Landeros, R., R. Reck, and R.E. Plank. "Maintaining BuyerSupplier Partnerships," International Journal of Purchasing and Materials Management, (31:3), Summer 1995, pp. 3-11.

Maloni, M.J. and W.C. Benton. "Supply Chain Partnerships: Opportunities for Operations Research," European Journal of Operations Research, (101), 1997, pp. 419-429.

Naylor, J.B., M.N. Naim, and D. Berry. “Leagility: Integrating the Lean and Agile Manufacturing Paradigms in the Total Supply Chain," International Journal of Production Economics, (62), 1999, pp. 107-118.

Saaty, T.L. The Analytic Hierarchy Process, McGraw-Hill, New York, NY, 1980.

Simon, H.A. Administrative Behavior: A Study of Decision-Making Processes in Administrative Organizations, Free Press, 1993.

Slack, N., S. Chambers, C. Harland, A. Harrison, and R. Johnston. Operations Management, Pitman Publishing, London, 1995.

Stevens, G.C. "Integrating the Supply Chain," International Journal of Physical Distribution and Materials Management, (19:8), 1989, pp. 3-8.

van Weele, Van A.J. Purchasing Management: Analysis, Planning and Practice, Chapman \& Hall, London, 1994.

Von Winterfeldt, D. and W. Edwards. Decision Analysis and Behavioral Research, Cambridge University Press, Cambridge, 1986. 